\title{
Conciliar no Tribunal é possível? Uma análise da experiência do Tribunal de Justiça do Estado do Rio Grande do Norte
}

\author{
Is conciliation in Courts of Appeal possible? An analysis of the experience of the Court of \\ Appeal in the State of Rio Grande do Norte
}

Elias Jacob de Menezes Neto *

Igor da Silva Gomes **

\begin{abstract}
REFERÊNCIA
MENEZES NETO, Elias Jacob; GOMES, Igor da Silva. Conciliar no Tribunal é possível? Uma análise da experiência do Tribunal de Justiça do Estado do Rio Grande do Norte. Revista da Faculdade de Direito da UFRGS, Porto Alegre, n. 42, p. 172-193, abr. 2020. DOI: <https://doi.org/10.22456/0104-6594.83978>.
\end{abstract}

\begin{abstract}
RESUMO
A Resolução no 125/2010 do Conselho Nacional de Justiça foi um marco importante para a criação de políticas públicas de resolução adequada dos conflitos, o que foi ampliado pela entrada em vigor do Código de Processo Civil de 2015. Nesse contexto, o presente artigo busca compreender a viabilidade das práticas conciliatórias no $2^{\circ}$ grau de jurisdição. Para tanto, realiza, a partir da metodologia de estudo de caso, uma análise da experiência do TJRN, especificamente do seu Núcleo de Conciliação. Utiliza dados do próprio órgão sobre as audiências, limitando o escopo aos anos de 2016 e 2017. Procede, ainda, com análise doutrinária e legislativa, sendo o estudo de relevância para exteriorizar a efetividade (ou não) do método consensual de resolução de disputas. Conclui-se que o TJRN tem trazido resultados positivos, chegando, no ano de 2017 , ao índice de êxito de $34 \%$ no Núcleo de Conciliação e 1,6\% no Tribunal como um todo, números acima da média nacional.
\end{abstract}

\section{PALAVRAS-CHAVE}

Conciliação. Tribunal de Justiça do Rio Grande do Norte. Políticas Públicas de Resolução de Conflitos.

\begin{abstract}
The CNJ's (Brazilian National Council of Justice) Resolution $n^{\circ}$ 125/2010 was an important landmark for create public policies for the adequate resolution of conflicts, which was amplified after the Brazilian Code of Civil Procedure of 2015. This research aims to understand if it's possible to use conciliation in Courts of Appeal. In order to do so, it analyses data from conciliation sessions held at the TJRN/NC (Conciliation Chamber of the Courts of Appeal at the state of Rio Grande do Norte/Brazil) between 2016 and 2017. In addition, it analyses the current theoretical and legal framework on conflict resolution. It concludes that TJRN has been achieving positive results, reaching, in 2017, a successful rate of 34\% at the TJRN/NC and of $1.6 \%$ on all Court levels, numbers above the national average.
\end{abstract}

\footnotetext{
* Mestre e Doutor em Direito Público pela Universidade do Vale do Rio dos Sinos. Professor adjunto do curso de Direito da Universidade Federal do Rio Grande do Norte, campus de Caicó/RN. Coordenador do Laboratório de Governança Pública da UFRN.

** Bacharel em Direito pela Universidade Federal do Rio Grande do Norte (UFRN). Pós-graduando (especialização lato sensu) em Direito Processual Civil com ênfase na Mediação e na Conciliação pela Escola Superior da Magistratura da Paraíba (ESMA PB/TJPB). Advogado na área de Direito Civil. Conciliador Judicial do Tribunal de Justiça do Estado do Rio Grande do Norte, cadastrado no Conselho Nacional de Justiça (CNJ), com atuação desde Novembro de 2016. Exerce atualmente o cargo de Subdelegado da Comunidade Internacional de Especialistas em Métodos Alternativos de Solução de Conflitos e Justiça Restaurativa no Brasil (CEMAJUR INTERNACIONAL).
} 


\section{KEYWORDS}

Conciliation. Court of Appeal of Rio Grande do Norte.

\section{SUMÁRIO}

1. Introdução. 2. A Política de Resolução Adequada de Disputas. 3. Meios Consensuais de Resolução de Conflitos: a conciliação e a Mediação. 4. Os Centros Judiciários de Solução Consensual de Conflitos e Cidadania (CEJUSC'S) e a sua composição no Tribunal de Justiça do Estado do Rio Grande do Norte. 5. A conciliação no tribunal de justiça do Estado do Rio Grande do Norte. 6. Conclusão. Referências. Dados da publicação.

\section{INTRODUÇÃ̃O}

Falar em acúmulo de processos no Poder Judiciário nacional já não é algo inédito, mas que continua a causar desconfortos em todas as pessoas que o compõem e aos que dele necessitam, tendo em vista que os recursos materiais e humanos limitados terminam por causar a morosidade e descrédito existente para com todo o sistema de justiça.

O Conselho Nacional de Justiça (CNJ), através do relatório anual intitulado "Justiça em Números", demonstrou que o Poder Judiciário encerrou o ano de 2016 com 79,7 milhões de processos em tramitação no Brasil. Foi constatado um crescimento de 2,7 milhões de processos, ou seja, um aumento de 3,6\% em consideração ao ano anterior (INSERIR REFERÊNCIA). - Não irei referenciar, professor Elias, em decorrência de que, na fase inicial da produção deste trabalho, estava referenciado e o senhor pediu para retirar a referência, haja vista que, preferencialmente, deve-se evitar referências na introdução.

Ao se recorrer ao Poder Judiciário como forma de garantir um direito ou uma simples declaração de existência ou inexistência de determinada situação jurídica (previsão do art. 19 do Código de Processo Civil de 2015), o cidadão sempre se deparou com um sistema monótono, no qual se instaurava o processo, em sua maioria derivado de um litígio, no qual as partes se digladiavam até as alegações finais (fase final do procedimento comum) e, posteriormente, um terceiro imparcial, representando o Estado (Juiz), prolatava uma sentença, na qual, por meio de um livre-convencimento motivado, declarava com quem estava o direito.

Nesse sentido, por meio da sistemática da jurisdição, a maioria dos processos encerrava-se com uma mesma lógica: um vencido e um vencedor. Acontece que, por meio desta prática, se tornou rotineira a insatisfação do vencido, quiçá também do próprio vencedor, que nem sempre conseguia tudo o que queria. 
Deste modo, as partes, insatisfeitas com a sentença proferida, utilizam-se dos recursos a sua disposição, prolongando o conflito instaurado e congestionando ainda mais os acervos processuais em tramitação.

Observando-se isto, o Poder Judiciário buscou implementar métodos alternativos de resolução de conflitos como solução mediata para facilitar o funcionamento adequado e célere da máquina judiciária, proporcionando uma resposta efetiva e satisfatória aos jurisdicionados.

Assim, o Conselho Nacional de Justiça editou a Resolução nº 125, em 29 de novembro de 2010, a qual dispôs sobre a criação de uma Política Judiciária Nacional de Tratamento Adequado dos Conflitos de Interesses no âmbito de todo o Poder Judiciário, trazendo os institutos da Conciliação e Mediação como meios alternativos para resolução das demandas.

Com a promulgação do Código de Processo Civil de 2015 e a obrigatoriedade trazida pelo artigo 334, o qual instituiu em todos os processos que seguem o procedimento comum a realização de audiência de tentativa de conciliação, a política de resolução adequada de conflitos ganhou mais notoriedade.

É com a implementação de todo um sistema de resolução consensual dos conflitos, através da conciliação e mediação, métodos nos quais se retira o Estado-Juiz como responsável pelo exercício da jurisdição, e estabelece as partes como protagonistas e responsáveis pelo destino de sua demanda, que se objetiva elevar a qualidade da prestação jurisdicional, pois o que se busca não é tão-somente a prolação de uma decisão de mérito ao final do processo, mas também a satisfação das pessoas.

A obrigatoriedade da aplicação dos meios alternativos no processo de conhecimento, através das audiências de tentativa de conciliação previstas no art. 334 do Código de Processo Civil vigente, por exemplo, deixou clara a tentativa de diminuir o protagonismo do Judiciário como responsável por resolver todas as questões a ele apresentadas, passando esse papel para as próprias partes.

No entanto, destaca-se que nem sempre é possível a composição consensual na $1^{\mathrm{a}}$ instância do Poder Judiciário, vindo o processo a ser sentenciado e o vencido, inconformado, a fazer uso dos meios recursais disponíveis para reverter à situação. A partir disto, pode-se concluir que o conflito, responsável pela origem da demanda no $1^{\circ}$ grau, permanece, podendo, inclusive, ser ampliado durante sua tramitação pela $2^{\mathrm{a}}$ Instância do Poder Judiciário.

Assim, este estudo, conforme se pode extrair do próprio título, questiona se a política de resolução pacífica dos conflitos é aplicada no âmbito da $2^{\mathrm{a}}$ Instância do Poder Judiciário, mais especificamente nos processos que tramitam perante o Tribunal de Justiça do Estado do 
Rio Grande do Norte. Sendo a primeira resposta positiva, passar-se-á a analisar a estrutura, funcionamento e efetividade das técnicas da conciliação no âmbito do Tribunal de Justiça, comparando os níveis de êxito destas audiências com os obtidos pelos Juízos de $1^{\text {a }}$ Instância do TJRN e de outros tribunais, como forma de compreender a eficácia do referido mecanismo.

Para a consecução da pesquisa, far-se-á uso dos dados disponibilizados pelo próprio Tribunal de Justiça do Estado do Rio Grande do Norte, através do Núcleo Permanente de Métodos Consensuais de Solução de Conflitos (NUPEMEC), bem como será utilizado um procedimento de estudo bibliográfico sobre a temática, trazendo, ainda, elementos legislativos como forma de consubstanciar a discussão.

A pesquisa fica adstrita aos anos de 2016 e 2017, pois visa também observar a influência do Código de Processo Civil de 2015 na execução da prática consensual de conflitos.

A importância do trabalho é intrínseca a própria temática, pois em uma época em que a aplicação da Política de Resolução Adequada de Conflitos surge como a principal solução para a morosidade e congestionamento do Poder Judiciário, a realização de estudos que tragam informações sobre seus resultados, mesmo que incipientes, proporcionam uma perspectiva de êxito (ou não) dos meios empregados.

\section{A POLÍTICA DE RESOLUÇÃO ADEQUADA DE DISPUTAS}

A Constituição Federal de 1988 estabeleceu como um dos seus mandamentos fundamentais o acesso à justiça, o qual deve ser garantido a todos os cidadãos que necessitam ou venham a necessitar da intervenção do Estado-Juiz para resolver seus interesses.

Segundo o Conselho Nacional de Justiça (2016, p. 40), “o acesso à justiça está mais ligado à satisfação do usuário (ou jurisdicionado) com o resultado final do processo de resolução de conflito do que com o mero acesso ao Poder Judiciário". Assim, não se deve confundir acesso à justiça com acesso ao Poder Judiciário, sob pena de ferir a real finalidade daquele que é a consecução dos interesses das partes.

Nesse sentido, o Poder Judiciário, exercendo a jurisdição, tem o papel primordial de promover a prestação jurisdicional de forma célere e satisfatória, propiciando a resolução de contendas e a pacificação social. Acontece que, com o acúmulo de processos e a morosidade persistente em seus órgãos, o Poder Judiciário tem falhado em sua missão. 
Sobre a temática são acertados os ensinamentos de Cintra, Grinover e Dinamarco (2014, p. 44):

\begin{abstract}
Abrem-se agora os olhos, todavia, para todas essas modalidades de soluções de conflitos, tratadas como meios alternativos de pacificação social. Vai ganhando corpo a consciência de que, se o que importa é pacificar, torna-se irrelevante que a pacificação venha por obra do Estado ou por outros meios, desde que eficientes. Por outro lado, cresce também a percepção de que o Estado tem falhado muito em sua missão pacificadora, que ele tenta realizar mediante o exercício da jurisdição estatal e através das formas do processo civil, penal ou trabalhista.
\end{abstract}

Assim, objetivando uma solução efetiva para os problemas expostos, o Conselho Nacional de Justiça estabeleceu políticas públicas em Resolução Adequada de Disputas (RAD's), tendo como marco principal a edição da Resolução n ${ }^{0}$ 125/2010, a qual instituiu a Política Judiciária Nacional de Tratamento dos Conflitos e Interesses, tendente a assegurar a todos o direito à solução dos conflitos por meios adequados à sua natureza e peculiaridade (art. $1^{\mathrm{o}}$, caput).

A Resolução consignou que incumbe aos órgãos judiciários, nos termos do art. 334 do Código de Processo Civil combinado com o art. 27 da Lei de Mediação, antes da solução adjudicada mediante sentença, oferecer outros mecanismos de soluções de controvérsias, em especial os chamados meios consensuais, como a mediação e a conciliação (art. $1^{\circ}$, parágrafo único).

Essa nova tendência adotada pelo Poder Judiciário iniciou-se em 1970, com o sistema do Fórum de Múltiplas Portas (Multidoor Courthouse), desenvolvida por Frank Sander (1976), a qual se traduz da seguinte forma:

Esta organização judiciária proposta pelo Fórum de Múltiplas Portas (FMP) compõe-se de um poder judiciário como um centro de resoluções de disputas, com distintos processos, baseado na premissa de que há vantagens e desvantagens de cada processo que devem ser consideradas em função das características especificas de cada conflito. Assim, em vez de existir apenas uma "porta" - o processo judicial - que conduz à sala de audiência, o FMP trata de um amplo sistema com vários distintos tipos de processo que formam um "centro de justiça", organizado pelo Estado, no qual as partes podem ser direcionadas ao processo adequado a cada disputa. (CONSELHO NACIONAL DE JUSTIÇA, 2016, p. 40).

Nessa linha de raciocínio, é com adoção de métodos alternativos, principalmente a conciliação e a mediação, que se busca desafogar e desobstruir o Poder Judiciário. Seus 
benefícios não ficam adstritos à celeridade processual, mas também proporcionam a pacificação social, o empoderamento das partes, o exercício da cidadania e a construção de uma cultura de paz.

É pertinente o que prelecionam Cintra, Grinover e Dinamarco (2014, p. 45) ao afirmarem que a utilização dos meios consensuais de resolução de conflito apresentam duas características fundamentais para o processo, quais sejam: a) desformalização, que se traduz na quebra do formalismo processual, dando uma pronta resposta aos litígios apresentados; e a b) delegalização, a qual é marcada pela margem de liberdade ofertada às partes na solução da controvérsia.

Outros autores como Sales e Rabelo (2009, p. 12) ainda chegam a considerar os métodos de resolução adequada de conflitos como instrumentos de efetivação da democracia, tendo em vista que tais métodos de negociação procuram dar uma solução (ou até mais) aos litígios de maneira ativa, participativa, pacífica e inclusiva, valorizando o diálogo e a participação das partes na resolução.

Portanto, todos os argumentos trazidos levam a crer que a mudança de paradigma na forma de enfrentar os problemas decorrentes da adoção da jurisdição como única (ou, no mínimo, principal) forma de resolução de conflitos tem como cerne um ponto em comum: melhorar a prestação jurisdicional para o jurisdicionado e, por consequência, a imagem do Poder Judiciário, reaproximando-o da sociedade.

A aposta realizada é de altas consequências e levam a uma só pergunta: vai funcionar? E, nesse presente momento, só uma resposta é plausível: só o tempo e a prática dirão, mas que com os problemas batendo a porta diariamente do Judiciário, só resta acreditar e investir em sua aplicação.

\section{MEIOS CONSENSUAIS DE RESOLUÇÃO DE CONFLITOS: A CONCILIAÇÃO E A MEDIAÇÃo.}

O Código de Processo Civil de 2015 começou esclarecendo em seu art. $3^{\circ}$ que o Estado promoverá, sempre que possível, a solução consensual dos conflitos $\left(\S 2^{\circ}\right)$, devendo a conciliação, a mediação e outros métodos de solução consensual de conflitos serem estimulados por juízes, advogados, defensores públicos e membros do Ministério Público, inclusive no curso do processo judicial $\left(\S 3^{\circ}\right)$. 
Complementa o art. $4^{\circ}$ do CPC/2015 que as partes têm o direito de obter em prazo razoável a solução integral do mérito, incluída a atividade satisfativa, devendo todos os sujeitos do processo cooperarem entre si para que se obtenha, em tempo razoável, decisão de mérito justa e efetiva (art. $\left.6^{\circ}\right)$.

Nessa linha de raciocínio, deve-se atentar para o incentivo expresso à prática da conciliação e mediação como meios alternativos de resolução dos conflitos, inclusive no curso do processo judicial, ou seja, o legislador deixa clara sua intenção de provocar as partes a exercerem extrajudicialmente os meios alternativos, tudo objetivando a solução integral da disputa, de forma célere e satisfativa. É a evidente aspiração do Poder Judiciário com a consecução de seu fim primordial: a pacificação social.

Nada obstante, deve-se atentar para o fato do CPC/2015 ter trazido a expressão "sempre que possível”, em seu art. $3^{\circ}$, criando, assim, duas características elementares na aplicação dos métodos consensuais de resolução de controvérsias, quais sejam a facultatividade e a discricionariedade, pois, com exceção do que prevê o art. 334, a utilização dos meios consensuais de resolução de conflitos são facultados a discricionariedade do Magistrado que, a depender da casuística, remete (ou não) o processo para a negociação amigável.

Diferentemente do Código de Processo Civil de 1973, o Código de Processo Civil de 2015 trouxe vasta citação sobre os meios consensuais de resolução de conflitos, mais especificamente a conciliação e a mediação.

Como exemplo tem-se o art. 694 do CPC/2015, o qual manifesta a necessidade do empreendimento de todos os esforços para a solução consensual nas ações de família, devendo o juiz dispor do auxílio de profissionais de outras áreas do conhecimento para a mediação e a conciliação, podendo, ainda, a requerimento das partes, suspender o processo para a realização de mediação extrajudicial ou atendimento multidisciplinar.

No entanto, uma lacuna evidente no CPC/2015 é a ausência de conceituação para os institutos da conciliação e mediação, pois o legislador apenas disciplinou que:

Art. 165.[...]

$\S 2^{\mathrm{o}} \mathrm{O}$ conciliador, que atuará preferencialmente nos casos em que não houver vínculo anterior entre as partes, poderá sugerir soluções para o litígio, sendo vedada a utilização de qualquer tipo de constrangimento ou intimidação para que as partes conciliem.

$\S 3^{\circ} \mathrm{O}$ mediador, que atuará preferencialmente nos casos em que houver vínculo anterior entre as partes, auxiliará aos interessados a compreender as questões e os interesses em conflito, de modo que eles possam, pelo restabelecimento da comunicação, identificar, por si próprios, soluções consensuais que gerem benefícios mútuos. 
Percebe-se do teor do dispositivo normativo que o legislador ateve-se apenas a delinear os limites da atuação do conciliador e do mediador, não trazendo qualquer definição para o que venha a ser a conciliação ou a mediação. Por sua vez, o Manual de Mediação Judicial, produzido pelo Conselho Nacional de Justiça (2016, p. 20/21), trouxe a seguinte definição dos institutos referenciados:

A mediação pode ser definida como uma negociação facilitada ou catalisada por um terceiro. Alguns autores preferem definições mais completas sugerindo que a mediação é um processo autocompositivo segundo o qual as partes em disputa são auxiliadas por uma terceira parte neutra ao conflito ou por um painel de pessoas sem interesse na causa, para se chegar a uma composição. [...] A conciliação pode ser definida como um processo autocompositivo breve no qual as partes ou os interessados são auxiliados por um terceiro, neutro ao conflito, ou por um painel de pessoas sem interesse na causa, para assisti-las, por meio de técnicas adequadas, a chegar a uma solução ou a um acordo.

É perceptível que os conceitos apresentados são bastante semelhantes, mas se deve atentar, inicialmente, para uma diferença intrínseca a ambos. A conciliação é um processo autocompositivo breve, ou seja, na maioria dos casos em que esta é aplicada, bastam tãosomente uma ou poucas sessões, enquanto que a mediação é mais prolongada, pois se busca restabelecer a comunicação entre as partes, o que demanda mais tempo e, por consequência, sessões.

Trazendo uma visão doutrinária, Scavone Júnior (2016, p. 273) ensina que a conciliação corresponde à atividade do conciliador, sendo que:

O conciliador tenta demover as partes a solucionar o conflito acatando suas ponderações e alternativas para a resolução do conflito que, entretanto, depende da anuência das partes A mediação, sempre voluntária, é definida nos termos da justificativa do projeto que resultou na Lei 13.140/2015, como "o processo por meio do qual os litigantes buscam o auxílio de um terceiro imparcial que irá contribuir na busca pela solução do conflito". Esse terceiro não tem a missão de decidir, mas apenas de auxiliar as partes na obtenção da solução consensual.

Do mesmo modo, quanto ao instituto da mediação, prevista na Lei Federal $\mathrm{n}^{\mathrm{o}}$ 13.105/2015, esclarece Vasconcelos (2017, p. 89) que: 
Pois a mediação, é uma prática e seu método, modelos e estilos, com o apoio de um terceiro, o mediador ou conciliador, sendo retórica material, vivência transdisciplinar, arte, algo construído nos campos da experiência e da compreensão dialogal. Mediação é, como já destacamos neste livro, um meio de assegurar o diálogo aberto em suas alternâncias, que enseja as condições de possibilidade de construção de novos significados, transformando as (pré)compreensões do próprio conflito e integrando os horizontes dos mediandos. Com ela vai-se concretizando o princípio do consensualismo.

Buscando as semelhanças entre os institutos da conciliação e mediação, Cintra, Grinover e Dinamarco (2014, p. 47) relatam que ambos os mecanismos assemelham-se, pois se tem em comum a participação de um terceiro, particular e desinteressado na causa, e buscase a pacificação do conflito. Nada obstante, distinguem-se na medida em que a conciliação busca o acordo como fim do procedimento, enquanto que a mediação tem como finalidade o trabalho e desconstrução do conflito, sendo o acordo uma mera consequência, podendo, portanto, ocorrer ou não.

Diante de todas as definições e apontamentos trazidos pela doutrina, pode-se afirmar, por mais que de forma incipiente e sob pena de sofrer críticas severas, que os institutos da conciliação e mediação vieram para transformar a realidade do Poder Judiciário, sendo meios alternativos na resolução das disputas, todavia, tem-se que questionar a importância e eficácia destes para a resolução efetiva dos conflitos.

Ambos os institutos fazem parte de uma Política Adequada de Resolução de Conflitos e quando se fala em adequação deve-se ter em mente que o Poder Judiciário busca, antes de qualquer coisa, meios de solucionar não só o processo, encerrando-o, mas também alternativas viáveis que se identifiquem e tenham um ajustamento pertinente com a situação fática material que lhe é apresentada diariamente.

Contextualizando toda a conjuntura do Poder Judiciário anteriormente referida, tem-se um sistema de exercício da jurisdição onde as partes encontravam-se acostumadas com a metodologia impositiva, pois o meio de se encerrar o processo era tão-somente com a prolação de uma sentença, a qual não era construída pelas partes, mas (im)posta pelo Juízo, após um análise dos fatos e provas juntadas aos autos.

Ocorre que isso, a prática vem demonstrando diariamente, nem sempre deixava ambas as partes satisfeitas, o que fazia o processo perdurar no tempo e, diga-se de passagem, nos espaços físicos dos fóruns. A situação apresentada é inevitável, pois ao realizar uma interpretação dos fatos e/ou direito, o magistrado, protagonista no sistema jurisdicional, tem 
que declarar com quem se encontra o direito e, por consequência, com quem não estar, o que sempre deixará alguém insatisfeito.

Deste modo, é por meio da aplicação dos meios alternativos (adequados) de solução das disputas que se busca resolver esse problema de satisfação, pois se retira do Magistrado tamanha responsabilidade, entregando-a, por consequência, as partes.

Através da construção de um diálogo, seja em audiências de tentativa de conciliação ou sessões de mediação, a depender da casuística, um terceiro imparcial, em outras um serventuário da justiça, ou até mesmo um colaborador externo, utilizando-se de técnicas específicas, sem poder de julgamento, auxilia nas negociações, facilitando a comunicação e a edificação de propostas para a resolução da disputa.

Por fim, ao se chegar a um consenso, as partes terão percebido que foram elas as responsáveis por dizer como devem ser resolvidas as questões postas à discussão, tendo total consciência que a solução foi prolatada sem qualquer coação, imposição ou outro vício de consentimento.

Assim, a conciliação e a mediação, métodos consensuais e adequados de solução de contendas, funcionam na perspectiva de proporcionarem um deslocamento de responsabilidade e protagonismo. Sai a figura do magistrado, responsável por tão-somente homologar o que se foi debatido, e entra a figura das partes, proprietárias diretas, em regra, dos interesses discutidos.

Por mais que já utilizada há bastante tempo em outros ordenamentos jurídicos alienígenas, a exemplo dos Estados Unidos da América que, desde a década 70, por meio da teoria da Multidoor Courthouse, desenvolvida pelo professor emérito da Harvard Law School, Frank Sander, utiliza tais meios consensuais de resolução de controvérsias, no Brasil a implantação e aplicação da conciliação e mediação ainda é recente. Nada obstante decorridos quase 08 anos da edição da Resolução $n^{\circ}$ 125/2010 do CNJ, a efetivação dos métodos ainda é lento e gradual, o que vem sendo aos poucos impulsionado por outros comandos normativos instituídos pelo CPC/2015 e pela Lei Federal n 13.140/2015 (Lei de Mediação). 


\section{OS CENTROS JUDICIÁRIOS DE SOLUÇÃO CONSENSUAL DE CONFLITOS E CIDADANIA (CEJUSC'S) E A SUA COMPOSIÇÃO NO TRIBUNAL DE JUSTIÇA DO ESTADO DO RIO GRANDE DO NORTE}

A Resolução $n^{\circ}$ 125/2010 do Conselho Nacional de Justiça, em seu art. $8^{\circ}$, disciplina que os Tribunais deverão criar os Centros Judiciários de Solução de Conflitos e Cidadania (Centros ou Cejusc's), unidades do Poder Judiciário, preferencialmente, responsáveis pela realização ou gestão das sessões e audiências de conciliação e mediação que estejam a cargo de conciliadores e mediadores, bem como pelo atendimento e orientação ao cidadão.

O CPC/2015 reforçou o dever dos tribunais de criarem os Centros Judiciários de Solução Consensual de Conflitos e Cidadania, os quais também ficaram responsáveis pelo desenvolvimento de programas destinados a auxiliar, orientar e estimular a autocomposição, conforme pode se observar do art. 165.

Sob uma perspectiva microscópica, NEVES (2017, p. 66) relata que os Centros Judiciários de Solução de Conflitos e Cidadania (CEJUSC'S) retiram do juiz a atribuição de conciliar ou mediar às partes, por mais que, eventualmente, caso frustrada a tentativa no Centro, possa, ao longo do processo, realizar sessões de mediação ou conciliação. Assim complementa o autor:

\footnotetext{
Vejo como medida positiva porque o juiz nem sempre é a pessoa mais indicada para exercer tal atividade, primeiro porque pode não ter a técnica necessária e, em segundo, porque pode ser acusado de prejulgamento na hipótese de uma participação mais ativa na tentativa de obter a conciliação ou a mediação. Ao criar um órgão que não pode prejulgar porque não tem competência para julgar e formado por pessoas devidamente capacitadas, tais problemas são superados.
}

No tocante a sua estruturação, cada unidade de CEJUSC deve, obrigatoriamente, conforme disciplina o art. 10 da Resolução $n^{\circ} 125 / 2010-C N J$, ser formado por três setores específicos, quais sejam: 1) setor de solução de conflitos pré-processuais; 2) setor de solução de conflitos processuais; e 3) setor de cidadania.

Os Tribunais deverão ainda assegurar que nos Centros atue ao menos um servidor com dedicação exclusiva, capacitado em métodos consensuais de solução de conflitos, para a triagem e encaminhamento adequado de casos $\left(\S 2^{\circ}\right.$, art. $\left.9^{\circ}\right)$. 
Igualmente, os Centros contarão com um juiz coordenador e, se necessário, com 01 adjunto, aos quais caberão a sua administração e a homologação de acordos, bem como a supervisão do serviço de conciliadores e mediadores (art. $9^{\circ}$, caput).

Esclarece-se que, nos tribunais de justiça, os Centros deverão ser instalados nos locais onde existam dois Juízos, Juizados ou Varas com competência para realizar audiência nos termos do art. 334 do Código de Processo Civil vigente, sendo facultativa a implementação onde exista apenas um Juízo, Juizado ou Vara, conforme regulamenta o art. $8^{\circ}, \S \S 2^{\circ}$ e $4^{\circ}$ da Resolução nº 125/2010-CNJ.

O Conselho Nacional de Justiça estabeleceu que o prazo para instalação dos CEJUSC's nas comarcas das capitais dos Estados, bem como nas comarcas do interior seria concomitante à entrada em vigor do Código de Processo Civil de 2015, ou seja, março de 2016. Salientando-se que, enquanto não instalados, os Tribunais são responsáveis por implantar procedimentos de conciliação e mediação itinerante, utilizando-se dos conciliadores e mediadores cadastrados nos respectivos tribunais.

Os CEJUSC's, segundo a Resolução no 125/2010-CNJ, devem ser criados pelos Núcleos Permanentes de Métodos Consensuais de Solução de Conflitos (NUPEMEC's), os quais serão coordenados e compostos por magistrados da ativa ou aposentados e servidores, preferencialmente atuantes na área, conforme disciplina o art. $7^{\circ}$ da referida resolução, vejase:

Art. $7^{\circ}$ Os tribunais deverão criar, no prazo de 30 dias, Núcleos Permanentes de Métodos Consensuais de Solução de Conflitos (Núcleos), coordenados por magistrados e compostos por magistrados da ativa ou aposentados e servidores, preferencialmente atuantes na área, com as seguintes atribuições, entre outras:

I- desenvolver a Política Judiciária de tratamento adequado dos conflitos de interesses, estabelecida nesta Resolução;

II- planejar, implementar, manter e aperfeiçoar as ações voltadas ao cumprimento da política e suas metas;

III- atuar na interlocução com outros Tribunais e com os órgãos integrantes da rede mencionada nos arts. $5^{\circ}$ e $6^{\circ}$;

IV- instalar Centros Judiciários de Solução de Conflitos e Cidadania que concentrarão a realização das sessões de conciliação e mediação que estejam a cargo de conciliadores e mediadores, dos órgãos por eles abrangidos;

$\mathrm{V}$ - incentivar ou promover capacitação, treinamento e atualização permanente de magistrados, servidores, conciliadores e mediadores nos métodos consensuais de solução de conflitos;

VI- propor ao Tribunal a realização de convênios e parcerias com entes públicos e privados para atender aos fins desta Resolução;

VII- criar e manter cadastro de mediadores e conciliadores, de forma a regulamentar o processo de inscrição e de desligamento; 
VIII- regulamentar, se for o caso, a remuneração de conciliadores e mediadores, nos termos do art. 169 do Novo Código de Processo Civil combinado com o art. 13 da Lei de Mediação.

No Tribunal de Justiça do Estado do Rio Grande do Norte, o Núcleo Permanente de Métodos Consensuais de Solução de Conflitos (NUPEMEC) foi instituído em 06 de abril de 2011, por meio da Resolução $n^{0}$ 011/2011 - TJRN. Segundo a referida Resolução, o NUPEMEC/TJRN deve ser composto por:

Art. $1^{\circ}$ Criar o Núcleo Permanente de Métodos Consensuais de Solução de Conflitos do Poder Judiciário do Estado do Rio Grande do Norte composto pelos seguintes membros:

- 01 Desembargador, a quem caberá a presidência do Núcleo;

- 03 Juízes de Direito, cabendo a um deles a função de coordenação dos trabalhos;

- 01 servidor da ESMARN;

- 01 servidor do Programa Desenvolver;

- 01 servidor do Núcleo de Projetos;

- 01 servidor com formação em Psicologia;

- 01 servidor com formação em Estatística;

- 01 servidor da Secretaria de Informática;

- 01 servidor da Coordenação de Planejamento Estratégico.

O NUPEMEC já foi responsável pela criação dos CEJUSC's em diversas Comarcas do Estado, os quais serão posteriormente especificados, inclusive existindo 01 CEJUSC no próprio Tribunal de Justiça, o qual foi autorizada sua criação por meio da Resolução $n^{\circ}$ 015/2011-TJRN, de 13 de abril de 2011, e sua instalação realizada em 16 de junho de 2011.

Para adaptar-se à Resolução no 125/2010 do CNJ, o Tribunal de Justiça do Rio Grande do Norte editou novo ato normativo, a Resolução n ${ }^{\circ}$ 052/2011-TJ, de 24 de outubro de 2011, a qual em seu art. $3^{\circ}$ alterou a nomenclatura de Núcleo de Conciliação para Centro de Conciliação, veja-se:

Art. $3^{\circ}$. O Núcleo de Conciliação instituído pela Resolução $n^{\circ}$ 015/2011-TJ passa a denominar-se Centro de Conciliação do Tribunal de Justiça, substituindo-se, em todo o texto da referida Resolução, a expressão "Núcleo de Conciliação" por "Centro de Conciliação", assim como a palavra "Núcleo" por "Centro".

Por conseguinte, através da Resolução no 023/2011- TJRN, de 06 de julho de 2011, foi criado o Centro Judiciário de Solução de Conflitos e Cidadania de Natal (CEJUSC Natal), primeiro no Estado do Rio Grande do Norte, instalado no Fórum Miguel Seabra Fagundes, na capital do Estado. 
No mesmo ano, por meio da Resolução no 034/2011-TJRN, de 08 de agosto de 2011, foi criado o Centro Judiciário de Solução de Conflitos e Cidadania de Mossoró (CEJUSC Mossoró), instalado no Fórum Silveira Martins.

Com a entrada em vigor do Código de Processo Civil de 2015 e o Movimento pela Conciliação promovido pelo Conselho Nacional de Justiça, o NUPEMEC/TJRN ampliou a criação dos CEJUSC'S em todo Estado, tendo sido criado outros diversos, conforme demonstrado na Tabela 1, veja-se.

TABELA 1 - CEJUSC'S criados no Estado do Rio Grande do Norte pelo NUPEMEC/TJRN

\begin{tabular}{ccc}
\hline CEJUSC & DATA DE CRIAÇÃO & MUNICÍPIO \\
Princesa do Seridó & 12 de maio de 2016 & Currais Novos \\
Mato Grande & 11 de novembro de 2016 & João Câmara \\
Juvenal Lamartine & 22 de novembro de 2016 & Serra Negra do Norte \\
Amaro Cavalcanti & 22 de novembro de 2016 & Jardim de Piranhas \\
Vale do Apodi & 05 de dezembro de 2016 & Apodi \\
Caicó & 09 de fevereiro de 2017 & Caicó \\
Caraubeiras & 22 de fevereiro de 2017 & Caraúbas \\
Oficial de justiça Manoel & 09 de março de 2017 & Luís Gomes \\
Feitosa & & Macau \\
Macau & 28 de março de 2017 & Tangará \\
Terra de São Sebastião & 14 de junho de 2017 & Governador Dix-Sept Rosado \\
Tangará & 24 de julho de 2017 & São Miguel \\
São Miguel & 25 de julho de 2017 & Umarizal \\
Umarizal & 27 de julho de 2017 & Patu \\
Patu & 10 de agosto de 2017 & Jacha Esto
\end{tabular}

Fonte: Núcleo Permanente de Métodos Consensuais de Solução de Conflitos do Tribunal de Justiça do Estado do Rio Grande do Norte (2018)

Diferentemente dos CEJUSC'S Natal e Mossoró, instituídos por meio de Resolução do TJRN, os referenciados na Tabela 1 foram criados por meio de Portaria do próprio Juízo responsável pela sede da comarca onde está localizado, com auxílio e orientação direta do NUPEMEC, o qual disponibilizou, inclusive, instrutores para a realização de cursos de capacitação em conciliação e mediação nos termos da Resolução n 125/2010-CNJ. 
Com o advento da Resolução $n^{\circ}$ 033/2017-TJRN, de 23 de agosto de 2017, as comarcas de Serra Negra do Norte e Governador Dix-Sept Rosado foram agregadas as comarcas de Caicó e Mossoró respectivamente, trazendo consigo seus CEJUSC's.

Deste modo, existe atualmente no Estado do Rio Grande do Norte um total de 15 CEJUSC's, contudo estão em pleno funcionamento apenas os de: 1) Natal; 2) Mossoró; 3) Pau dos Ferros; 4) João Câmara; 5) Jardim de Piranhas; 6) Parnamirim; 7) Caicó; e o Núcleo de Conciliação do $2^{\circ}$ Grau, o qual é objeto do presente estudo e passar-se-á a ser analisado no tópico seguinte.

\section{A CONCILIAÇÃO NO TRIBUNAL DE JUSTIÇA DO ESTADO DO RIO GRANDE DO NORTE}

Chegando ao cerne deste estudo, analisar-se-á a prática dos métodos consensuais de composição de conflito, mais especificamente a conciliação, no âmbito do Tribunal de Justiça do Estado do Rio Grande do Norte.

Cabe consignar que os dados a serem aqui trabalhados dão conta apenas dos anos de 2016 e 2017, considerando a análise da influência do Código de Processo Civil de 2015, o qual trouxe a obrigatoriedade da realização das audiências preliminares de conciliação (art. 334) e a possibilidade de outras audiências de conciliação ou mediação ao longo do processo (art. $2^{\circ}, \S 3^{\circ}$ ) e entrou em vigor apenas no mês de março de 2016.

Nesse prisma, os dados disponibilizados pelo Núcleo Permanente de Métodos Consensuais de Solução de Conflitos (NUPEMEC) referem-se à conciliação realizada pelo Núcleo de Conciliação do $2^{\mathrm{a}}$ Grau do TJRN, excluindo-se as tentativas de conciliação realizadas pelo próprio órgão de julgamento colegiado, as quais serão analisadas segundo os dados apresentados pelo Conselho Nacional de Justiça, através do relatório anual "Justiça em Números".

Inicialmente, constatou-se que no ano de 2016 foram aprazadas 497 audiências pelo Núcleo de Conciliação do TJRN, sendo realizadas um total de 264, das quais foram obtidas 78 propostas de acordo e 34 acordos realizados, chegando à margem de $12,87 \%$ de êxito nas conciliações.

No ano subsequente (2017), foram aprazadas 610 audiências e realizadas apenas 290, sendo formuladas 128 propostas de acordo, as quais ocasionaram 100 acordos, totalizando $34,48 \%$ de êxito nas conciliações. 
Para facilitar o entendimento, encontra-se demonstrado com clareza o trabalho desenvolvido no Núcleo de Conciliação do $2^{\circ}$ Grau do TJRN no ano de 2016, conforme informações descritas na Tabela 2:

TABELA 2 - Audiências aprazadas, frustradas, realizadas e acordos realizados no âmbito do Núcleo de Conciliação do TJRN no ano de 2016

\begin{tabular}{cc}
\hline SITUAÇÃO & QUANTIDADE \\
Pautados & 497 \\
Reaprazamentos & 10 \\
Processos em que houve ausência parcial & 157 \\
Processos em que houve ausência total & 66 \\
Audiências realizadas & 264 \\
Propostas de Acordo & 78 \\
Acordos & 34 \\
Pessoas atendidas & 1071 \\
\hline
\end{tabular}

Fonte: Núcleo Permanente de Métodos Consensuais de Solução de Conflitos do Tribunal de Justiça do Estado do Rio Grande do Norte (2018)

Observe-se que foram realizadas, durante as audiências, 78 propostas de acordo, das quais apenas 43,58\% destas foram acolhidas pela parte contrária, restando exitosa a conciliação. Assim, frise-se, novamente, que o total de êxito nas audiências de tentativa de conciliação no Núcleo de Conciliação foi de 12,87\%.

Em análise comparativa, dados do Conselho Nacional de Justiça, através do relatório anual "Justiça em Números", indicam que a média conciliatória do $1^{\circ}$ grau de jurisdição do TJRN foi de $18,8 \%$, enquanto que a média nacional do $1^{\circ}$ grau de jurisdição no Poder Judiciário Estadual foi de 13,6\%, ambas superiores ao Núcleo de Conciliação do $2^{\circ}$ grau do TJRN. Liderando os índices de conciliação na $1^{\mathrm{a}}$ instância, tem-se a Justiça do Trabalho, com percentual de $32,2 \%$ de êxito.

Ademais, ao se considerar o índice de conciliação de todo o tribunal, somando-se as audiências realizadas pelo Núcleo de Conciliação e pelas próprias câmaras, o TJRN tem uma taxa de êxito de 1,5\%, média insignificante, mas ainda superior a média nacional que é de $0,4 \%$. 
Um dos problemas na consecução da conciliação no $2^{\circ}$ Grau de Jurisdição é a quantidade de audiências frustradas, haja vista a ausência de uma ou ambas as partes na audiência, demonstrada pelos dados trazidos na Tabela 2 (percentual de 45,79\%).

Por conseguinte, quanto ao ano de 2017, a Tabela 3 demonstra a evolução das audiências realizadas pelo Núcleo de Conciliação do Tribunal de Justiça do Estado do Rio Grande do Norte, veja-se.

TABELA 3 - Dados quantitativos das audiências aprazadas, frustradas, realizadas e acordos formulados no âmbito do Núcleo de Conciliação do TJRN no ano de 2017

\begin{tabular}{cc}
\hline SITUAÇ̃̃O & QUANTIDADE \\
Pautados & 610 \\
Reaprazamentos & 43 \\
Processos em que houve ausência parcial & 209 \\
Processos em que houve ausência total & 68 \\
Audiências realizadas & 290 \\
Propostas de Acordo & 128 \\
Acordos & 100 \\
Pessoas atendidas & 1476
\end{tabular}

Fonte: Núcleo Permanente de Métodos Consensuais de Solução de Conflitos do Tribunal de Justiça do Estado do Rio Grande do Norte (2018)

Em face dos dados trazidos, infere-se que houve uma ampliação na quantidade de audiências incluídas em pauta se comparado ao ano de 2016, aumento este na margem aproximada de $20 \%$.

No tocante ao índice de êxito nas conciliações realizadas, depreende-se que este atingiu o percentual de $34,48 \%$, média que ultrapassa os índices do $1^{\circ}$ Grau da Justiça do Trabalho $(32,2 \%)$.

A análise comparativa dos dados trazidos na Tabela 2, referentes ao ano de 2016, com os dados apresentados pela Tabela 3, referentes ao ano de 2017, demonstram um aumento de mais de $100 \%$ na taxa de êxito nas conciliações no âmbito do Núcleo de Conciliação do $2^{\circ}$ Grau do TJRN em apenas um ano. 


\section{CONCLUSÃO}

É possível constatar, a princípio, que o TJRN, através do NUPEMEC, tem propagado consideravelmente a Política de Resolução Adequada dos Conflitos, difundida pela Resolução $n^{\circ} 125 / 2010$ do CNJ, tanto é que entre 12/05/2016 até o início do ano de 2018 foram criados 15 CEJUSC'S em todo o Estado.

Os resultados desse incentivo estão nos índices de conciliação apresentados pelo CNJ, através de seu relatório anual "Justiça em Números". No ano de 2016, enquanto que o índice de conciliação nacional no $1^{\circ}$ grau foi de $13,6 \%$, o TJRN atingiu 18,8\%. No $2^{\circ}$ grau de jurisdição não foi diferente, sendo a média anual de $0,4 \%$, enquanto que o TJRN alcançou $1,5 \%$.

Para se analisar esses índices tem-se que considerar que o Conselho Nacional de Justiça faz um cálculo baseado na quantidade de sentenças proferidas por meio do exercício da jurisdição e sentenças homologatórias. Quando se compara os índices de conciliação, no ano de 2016, tem-se que no Núcleo de Conciliação do $2^{\circ}$ grau do TJRN é de $12,87 \%$, enquanto que o próprio tribunal não ultrapassa $1,5 \%$.

Com o intuito de compreender a diferença exposta, deve-se atentar para o fato de que todos os processos que são remetidos ao Núcleo de Conciliação são postos em pauta para realização de audiências de conciliação por profissionais capacitados nas técnicas do método alternativo de resolução de conflito. Diferente disso, tem-se que a conciliação a ser realizada pelas próprias câmaras no tribunal é facultativa e fica limitada a discricionariedade dos desembargadores em realizá-la ou não.

A facultatividade anteriormente referenciada se dá pelo fato de que o Código de Processo Civil de 2015 disciplinou que a conciliação e outros meios de resolução consensual dos conflitos devem ser incentivados durante todo o processo, contudo não obriga $o$ magistrado a realizar audiências em outras fases do processo, senão inicialmente, conforme previsto no art. 334 do CPC/2015.

Assim, fica a cargo dos desembargadores que constituem o órgão julgador tentarem ou não compor consensualmente o conflito por meio da conciliação, fato que por si só obstaculiza sua aplicação.

Além da discricionariedade, outro entrave existente para a aplicação desses métodos nas turmas julgadoras do tribunal é o próprio fato de serem os desembargadores os responsáveis pela realização da audiência, pois, por mais que capacitados na técnica jurídica, os membros 
que compõem os órgãos julgadores do tribunal não detém da adequada formação para a aplicação das técnicas da conciliação.

Nada obstante, ainda que os desembargadores detivessem das técnicas da conciliação, o simples fato de terem a titulação de julgadores já é motivo de constrangimento e intimidação das partes, as quais sabem que se não houver a composição consensual naquele momento, serão aqueles próprios magistrados que julgarão o processo.

Outro problema que persiste na conciliação realizada pelos órgãos julgadores permeia a formação de um pré-julgamento por parte dos magistrados, estes que se atém aos fatos e argumentações trazidos durante a tentativa de conciliação, mesmo que involuntariamente, e podem levar essa concepção para o momento do julgamento, causando verdadeira lesão à imparcialidade e neutralidade., Deste modo, sendo significativa a diferença nos índices de êxito no tribunal para o do Núcleo de Conciliação, conclui-se, inicialmente, que deve haver uma ampliação na remessa dos processos para o referido Núcleo, com vistas à realização adequada de tentativas de composição do conflito por terceiros, experientes nas técnicas da conciliação e/ou mediação, sem poder de julgamento, antes do ingresso em pauta de julgamento.

Os resultados dessa conclusão já podem ser percebidos pelos dados trazidos pelo NUPEMEC no ano de 2017, os quais demonstram que foram pautados 610 processos para audiência no Núcleo de Conciliação do $2^{\circ}$ grau, o que gerou uma margem de 34,48\% de êxito nas conciliações. Aumento de mais de 100\%, quando comparado ao ano de 2016.

Um problema verificado e que, se resolvido, pode melhorar os percentuais de êxito no âmbito do Núcleo e, por consequência, de todo o tribunal é a presença das partes nas audiências, pois se observou que a ausência de uma ou ambas as partes atingiu o percentual de $45,79 \%$.

Nesse prisma, considerando que, segundo o NUPEMEC, todos os advogados são intimados das audiências, restando cientificadas as partes quanto à existência das audiências, a ausência das desta decorre do seu próprio desestímulo em se fazer presente e tentar a composição amigável da disputa.

Os fatores que desestimulam as partes a tentarem a composição consensual do conflito na $2^{\mathrm{a}}$ instância podem ser dos mais diversos, seja pela volição em demonstrar que está correto logo após ter seus interesses denegados por sentença de $1^{\circ}$ grau, seja pela impossibilidade de se comunicar com a parte contrária. 
É perceptível que uma forma de se evitar sequer a existência desses processos no $2^{\circ}$ grau é o incentivo dos métodos de resolução adequada de conflitos na gênesis do conflito, qual seja a $1^{\mathrm{a}}$ instância, pois o agravamento do conflito é inevitável quando se atinge a instância recursal.

Não se pode ainda descartar a hipótese de que o desgaste e cansaço das partes diante da morosidade do judiciário facilite a composição consensual na $2^{\mathrm{a}}$ instância, contudo situações como essas ainda são poucas, a considerar os índices de êxito conciliatório apresentados.

Nada obstante a todas as informações trazidas, tem-se que o Tribunal de Justiça do Estado do Rio Grande do Norte, por mais que seja um dos menores do país, está caminhando progressivamente na adequação com os ditames trazidos pela Resolução no 125/2010 do CNJ, tornando-se referência na aplicação dos métodos consensuais de resolução de conflitos.

Da mesma forma, o Núcleo de Conciliação do $2^{\circ}$ grau, pelos números trazidos, demonstra, ainda que de forma inicial, que conciliar é possível e tem resultados positivos para construção de uma política alternativa que venha, de forma mediata, a solucionar os problemas do Poder Judiciário com a morosidade e falta de efetividade.

Portanto, a experiência trazida pelo Tribunal de Justiça do Estado do Rio Grande do Norte é que conciliar no $2^{\circ}$ grau é legal e merece ser cultivada, ampliada e difundida, para que assim se possa proporcionar ao jurisdicionado o mais pleno acesso à justiça e não tão-somente o acesso ao judiciário.

\section{REFERÊNCIAS}

BRASIL. CONSELHO NACIONAL DE JUSTIÇA. Azevedo, André Gomma de (Org.). Manual de Mediação Judicial. 6. ed. 392 p. Brasília/DF, 2016.

. CONSELHO NACIONAL DE JUSTIÇA. Resolução $n^{\circ} 125$ de 29 de novembro de 2010. Dispõe sobre a Política Judiciária Nacional de tratamento adequado dos conflitos de interesses no âmbito do Poder Judiciário e dá outras providências. Disponível em: < http://www.cnj.jus.br/busca-atos-adm?documento=2579>. Acesso em: 27 jan. 2018.

. CONSELHO NACIONAL DE JUSTIÇA. Justiça em Números: 2017 ano-base 2016.

Brasília: $\quad$ CNJ, $2017 . \quad 190 \quad$ p. $\quad$ Disponível $\quad$ em:< http://www.cnj.jus.br/files/conteudo/arquivo/2017/12/b60a659e5d5cb79337945c1dd137496c. pdf $>$. Acesso em: 14 mar. 2018.

Lei Federal $\mathrm{n}^{\circ}$ 13.105, de 16 de março de 2015. Código de Processo Civil. Disponível em:< http://www.planalto.gov.br/ccivil_03/_ato2015-2018/2015/lei/113105.htm>. Acesso em: 27 jan. 2018. 
CINTRA, A. C. de A.; GRINOVER, A. P.; DINAMARCO, C. R. Teoria Geral do Processo. 30. ed., rev., atual., amp. São Paulo: Malheiros, 2014.

NEVES, D. A. A. Manual de Direito Processual Civil. Volume Único. Conforme novo CPC. 9. ed., rev., atual. Salvador: JusPodivm, 2017.

RIO GRANDE DO NORTE. Tribunal de Justiça. Resolução $n^{\circ}$ 011/2011-TJ, de 06 de abril de 2011. Institui o Núcleo Permanente de Métodos Consensuais de Solução de Conflitos no Poder Judiciário do Estado do Rio Grande do Norte e dá outras providências. Disponível em: $<$ http://www.tjrn.jus.br/index.php/precatorios/rpv/doc_download/2023-resolucao-tjrn112011-cria-o-nupemec $>$. Acesso em: 18 jan de 2018.

. Tribunal de Justiça. Resolução $n^{\circ}$ 015/2011-TJ, de 13 de abril de 2011. Autoriza a criação e instalação do Núcleo de Conciliação no âmbito do Tribunal de Justiça e dá outras providências. Disponível em:< www.tjrn.jus.br/index.php/legislacao/resolucoes/doc_download/255-15>. Acesso em: 23 fev. de 2018.

. Tribunal de Justiça. Resolução $n^{\circ}$ 023/2011-TJ, de 06 de julho de 2011. Cria o Centro Judiciário de Solução de Conflitos e Cidadania de Natal. Disponível em: $<$ http://sistemasdis01.tjrn.jus.br/servidorDeArquivos/pages/documentos/5850.pdf>. Acesso em 23 jan. 2018.

SALES, L. M. de M.; RABELO, C. de M. S. Meios consensuais de solução de conflitos: Instrumentos de democracia. 2009. Revista de informação legislativa, v. 46, n. 182, p. 75-88, abr./jun. 2009 Disponível em: <http://www2.senado.leg.br/bdsf/handle/id/194916>. Acesso em 23 jan. 2018.

SCAVONE JUNIOR, L. A. Manual de Arbitragem, Mediação e Conciliação. 7. ed., rev., atual., amp. Rio de Janeiro: Forense, 2016.

VASCONCELOS, C. E. de. Mediação de Conflitos e Práticas Restaurativas. 5. ed., rev., atual., amp. São Paulo: Método, 2017.

\section{DADOS DA PUBLICAÇÃO}

Categoria: artigo submetido ao double-blind review.

Recebido em: 17/08/2018

Aceito em: 25/10/2018 


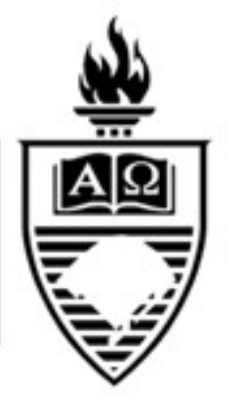

